\title{
Calculation of Rotational Barriers of 4-Acy- loxy-4'-N-N-Butylcarbamyloxy-Biphenyls by Molecular Calculation and Linear Free Energy Relationships
}

\author{
Shu-Hsien Lin ${ }^{1,2}$, Yu-Fang Shen ${ }^{3,4}$, Chun-Yu Chiou ${ }^{1}$, Gialih Lin ${ }^{1}$, g. and Gan-Hong Chen"5, g \\ ${ }^{1}$ Department of Chemistry, National Chung-Hsing University, Taichung, Taiwan \\ ${ }^{2} 3$ P Printing Medical Research Center, China Medical University Hospital, Taichung, Taiwan \\ ${ }^{3}$ Department of Bioinformatics and Medical Engineering, Asia University, Taichung, Taiwan \\ ${ }_{3}^{4} 3$ Printing Medical Research Institute, Asia University, Taichung, Taiwan \\ ${ }^{5}$ Department of Culinary Art Management, Taiwan Hospitality \& Tourism College, Hualien, Taiwan \\ $g$ : the authors contributed equally to this work.
}

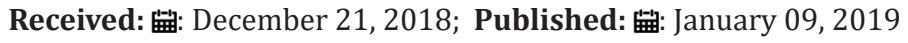

*Corresponding author: Gan-Hong Chen, Department of Culinary Art Management, Taiwan Hospitality \& Tourism College, Taiwan

\begin{abstract}
Rotational barriers of ten 4-acyloxy-4'-N-n-butylcarbamyloxy-biphenyls were calculated by density functional theory. Linear free energy relationships between rotational barriers and reduced mass existed in these compounds. Rotational barriers of these compounds from dihedral angle of $45^{\circ}$ to $90^{\circ}\left(\Delta E_{90}\right.$ 's) were linearly correlated with the inverse of reduced mass $\left(1 / \mathrm{m}^{\prime}\right)$. Thus, this rotational mechanism was just a simple physical rotation of an object about its center axis. On the other hand, rotational barriers of these compounds from dihedral angle of $45^{0}$ to $0^{0}($ $\Delta E_{0}$ 's)) were dependent upon both $1 / \mathrm{m}^{\prime}$ and the vibrational energy difference at the C(1)-C(1') bond near dihedral angle of $0^{\circ}\left(\sigma^{*}\right.$ 's). Values of $E_{v i b}=\left(\Delta E_{v i b}=(1 / 2)\right.$ were linearly correlated with the inverse of the root of reduced mass $\left(1 / \sqrt{ } \mathrm{m}^{\prime}\right)$. Thus, the $\Delta \mathrm{E}_{0}$ values calculated from density functional theory combined both physically rotational energy barrier, $\Delta \mathrm{E}_{90}$, and vibrational (or stretching) energy barrier, $\Delta E_{v i b}$. A two-step mechanism for the rotation of biphenyl from dihedral angle of $-45^{0}$ to $45^{\circ}$ through the intermediate with an increasing $\mathrm{C}(1)-\mathrm{C}\left(1^{\prime}\right)$ pivot bond length of $0.027 \AA$ was proposed. Accordingly, values of the bond length incensement of these ten biphenyls were calculated to be from 0.037 to $0.046 \AA$. Thus, the experimental $\Delta \mathrm{E}_{0}$ values were estimated to be the calculated $\Delta \mathrm{E}_{0}$ values minus the $\Delta E_{v i b}$ values.
\end{abstract}

Keywords: Rotational Barriers; Density Functional Theory; Biphenyls; Gaussian; Linear Free Energy Relationship

\section{Introduction}

One of the paradoxical results in Chemistry was that the rotational barriers of biphenyls obtained from experiments were significant different to those calculated by quantum mechanism. In the gas-phase experiments, Bastiansen and Samdal estimated the barriers from ground state (dihedral angle, $\phi=45^{\circ}$ ) to $\phi=0^{0}$ and $\phi=90^{\circ}$ to be $\Delta E_{0}=6.0 \pm 2.1 \mathrm{~kJ} / \mathrm{mol}$ and $\Delta E_{90}=6.5 \pm 2.0 \mathrm{~kJ} /$ mol, respectively [1]. Theoretical calculation for rotation barriers of biphenyl by different levels of basis sets of quantum mechanism was always active in this field since the second half of last century. Tsuzuki and Tanabe reported $\Delta E_{0}=13.93 \mathrm{~kJ} / \mathrm{mol}$ and $\Delta E_{90}=6.32$
$\mathrm{kJ} / \mathrm{mol}$ from $\mathrm{HF} / 6-31 \mathrm{G}^{* *}$ level of quantum mechanism calculation [2]. Rubio et al. found $\Delta E_{0}=12.93 \mathrm{~kJ} / \mathrm{mol}$ and $\Delta E_{90}=6.40 \mathrm{~kJ} /$ mol from $4 \mathrm{~s} 3 \mathrm{p} 1 \mathrm{~d} / 2 \mathrm{~s} 1 \mathrm{p}$ basis set level of quantum mechanism calculation [3]. Karpfen et al. estimated that the $\Delta E_{0}$ values were $13.8,16.3$, and $8.4 \mathrm{~kJ} / \mathrm{mol}$ and that the $\Delta E_{90}$ values were $6.3,7.5$, and $10.0 \mathrm{~kJ} / \mathrm{mol}$ by SCF, MP2, and B3LYP methods, respectively [4].

Values of $\Delta E_{0}$ were 13.0 and $8.4 \mathrm{~kJ} / \mathrm{mol}$ and $\Delta E_{90}$ were 5.0 and $7.3 \mathrm{~kJ} / \mathrm{mol}$ using the $6-311++\mathrm{G}(\mathrm{d}, \mathrm{p})$ basis set for SCF and B3LYP, respectively. By MP2/cc-pVQZ//MP2/6-31G* calculation, Tsuzuki et al. obtained $\Delta E_{0}$ and $\Delta E_{90}$ were 9.54 and $8.91 \mathrm{~kJ} / \mathrm{mol}$, 
respectively [5]. The best calculated values from Johansson and Olsen by coupled cluster including single and double excitations as well as triples correlations $(\operatorname{CCSD}(\mathrm{T}))$ from density functional theory (DFT) were $\Delta E_{0}=7.96 \mathrm{~kJ} / \mathrm{mol}$ and $\Delta E_{90}=8.79 \mathrm{~kJ} / \mathrm{mol}$, respectively [6]. In general, $\Delta E_{90}$ of biphenyl could be calculated to be very close to the experimental result by low level of quantum mechanism calculation. However, high level of quantum mechanism calculation made $\Delta E_{90}$ of biphenyl away from the experimental data. Thus, HF/6-31G** level was good enough for calculation of $\Delta E_{90}$ of biphenyl.

On the other hand, the calculated $\Delta E_{90}$ of biphenyl was difficult to match with the experimental data. Complicated levels of calculations not only lowered $\Delta E_{0}$ of biphenyl yet increased $\Delta E_{90}$ of biphenyl. Therefore, $\Delta E_{90}$ (rotational barrier of biphenyl from $\phi=$ $45^{\circ}$ to $\phi=90^{\circ}$ ) and $\Delta E_{0}$ (rotational barrier of biphenyl from $\phi=45^{\circ}$ to $\phi=0^{\circ}$ ) might be dominated by two different mechanisms. In order to test this ideal, ten 4,4'-disubstituted biphenyls [1-10] (Figure 1) [7-9], which were potent inhibitors of acetylcholinesterase, butyryl cholinesterase's and lipase, were chose to calculated $\Delta E_{0}$ and $\Delta E_{90}$ by HF/6-311G(d,p) method [10]. The reason why we chose 4,4'-disubstituted biphenyls for this study was because steric effects from 4,4'-positions for these compounds were most insignificant while the electronic or polar effect from these positions were important for these conformational (rotational) changes.

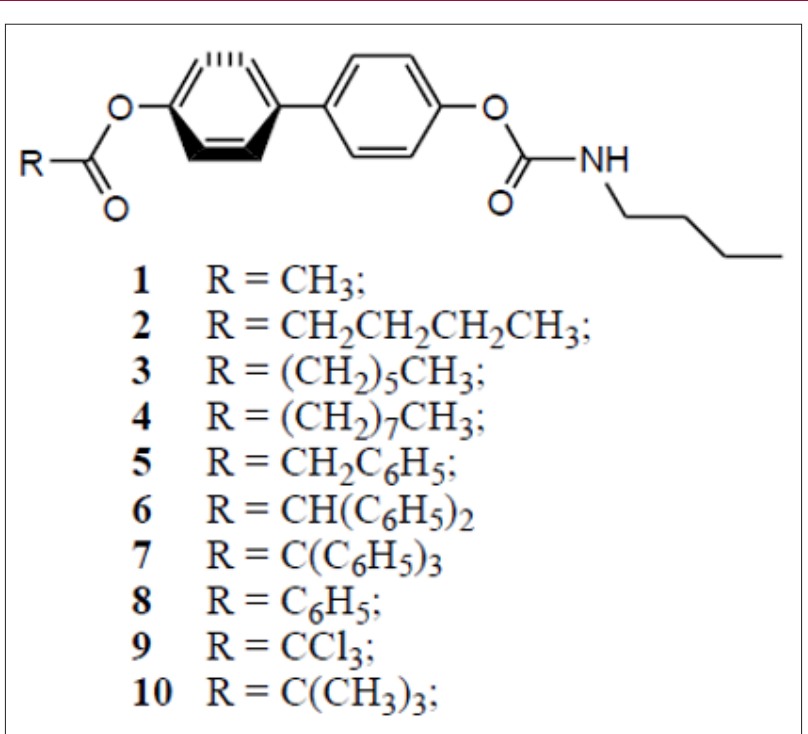

Figure 1: Chemical structures of compounds 1-10.

\section{Materials and Methods}

4-Acyloxy-4'-N-n-butylcarbamyloxy-biphenyls (1-10) were synthesized from biphenyl [7-9]. All DFT calculations were preformed from B3LYP method and basis function of 6-311G(d,p) by Gaussian 03 [10]. MM-2 energy minimization was performed by CS Chem 3D (version 6.0). Origin (version 6.0) was used for linear and nonlinear least-squares curve fittings $\Delta E_{90}$

\section{Results and Discussion}

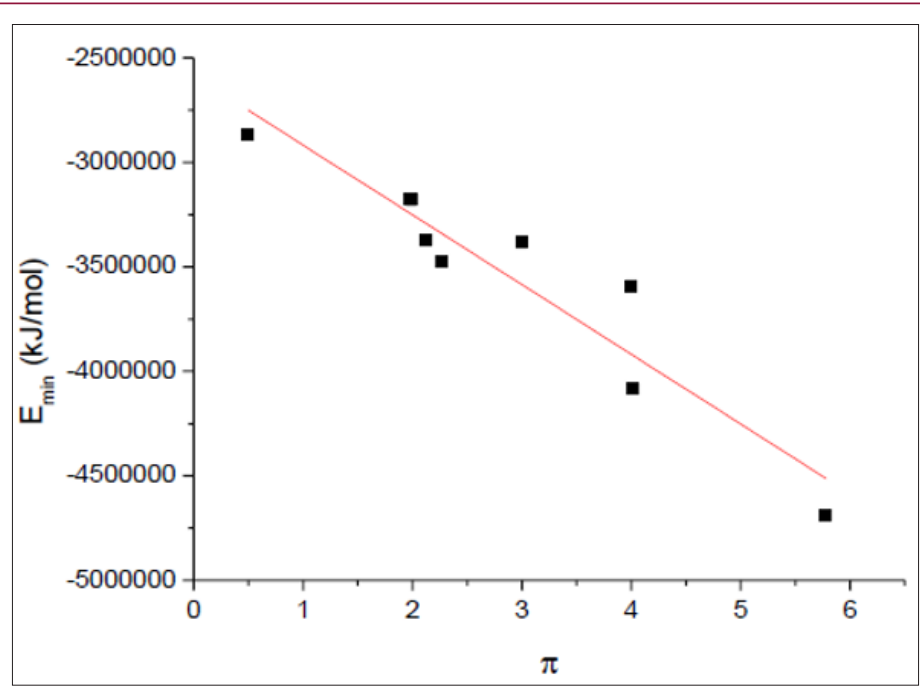

Figure 2: A linear correlation between Emin and Emin = -(2.6 \pm 0.1$) \times 106-(3.3 \pm 0.4) \times 105$ (kJ/mol); R=0.93777. 
The minimized energies (Emin's) of compounds 1-10 (except 9) calculated by HF/6-311G(d,p) method (Table 1) were linearly correlated with Hansch electronic values [11] (Figure 2). Thus, all electronic effects of all substituents were taken into consideration in HF/6-311G(d,p) calculation. Similar to the rotational spectroscopy for end-over-end rotation, rotational energy (EJ) was quantized as Eq. (1), where J and I were rotation quantum number (J=0, 1, 2, $3, .$.$) and moment of inertia, respectively [12].$

$$
E_{J}=J(J+1) \hbar^{2} / 2 I
$$

Table 1: Dihedral angles $\left(\phi^{\prime}\right.$ 's) and minimized energies $\left(\mathrm{E}_{\text {min's }^{\prime}}\right)$ for the ground states of biphenyls and energy barriers for rotations of biphenyls from $\phi=-45^{0}$ to $45^{0}$ through $0^{\circ}\left(\Delta E_{0}\right)$ and from $\phi=45^{0}$ to $135^{0}$ through $900\left(\Delta E_{90}\right)$ about the center axis.

\begin{tabular}{|c|c|c|c|c|}
\hline Compounds & $\phi$ (in degree) in ground state & Emin (kJ/mol) & $\Delta x a t=0^{0}(\mathbf{k J} / \mathbf{m o l})$ & $\Delta E_{90}(\mathbf{k J} / \mathbf{m o l})$ \\
\hline Biphenyl & 44.6 & -1208627 & 13.95 & 6.42 \\
\hline 1 & 46 & -2868465 & 14.36 & 6.05 \\
\hline 2 & 45.9 & -3178168 & 14.33 & 5.03 \\
\hline 3 & 45.9 & -3384598 & 14.25 & 6.05 \\
\hline 4 & 45.5 & -3591065 & 14.27 & 5.96 \\
\hline 5 & 45.9 & -3475192 & 14.17 & 5.85 \\
\hline 6 & 45.2 & -4082913 & 14.14 & 5.79 \\
\hline 7 & 46 & -4689459 & 14.24 & 5.93 \\
\hline 9 & 46 & -3371927 & 14.2 & 5.96 \\
\hline 10 & 45.4 & -6490148 & 14.24 & 5.92 \\
\hline
\end{tabular}

The moment of inertia (I) might be written as Eq. (2), where R and $\mathrm{m}^{\prime}$ were rotated distance and reduced mass, respectively.

$$
I=m_{1} m_{2} R^{2} /\left(m_{1}+m_{2}\right)=m^{\prime} R^{2}
$$

$\left(1 / \mathrm{m}^{\prime}\right)$ (Figure 3). Therefore, rotation of biphenyl from dihedral angle of 45 oto 90 -was just a simple physical rotation of an object about its center axis. Hence, both electronic and steric effects were insignificant in this mode of rotation.

was linearly correlated with the inverse of reduced mass

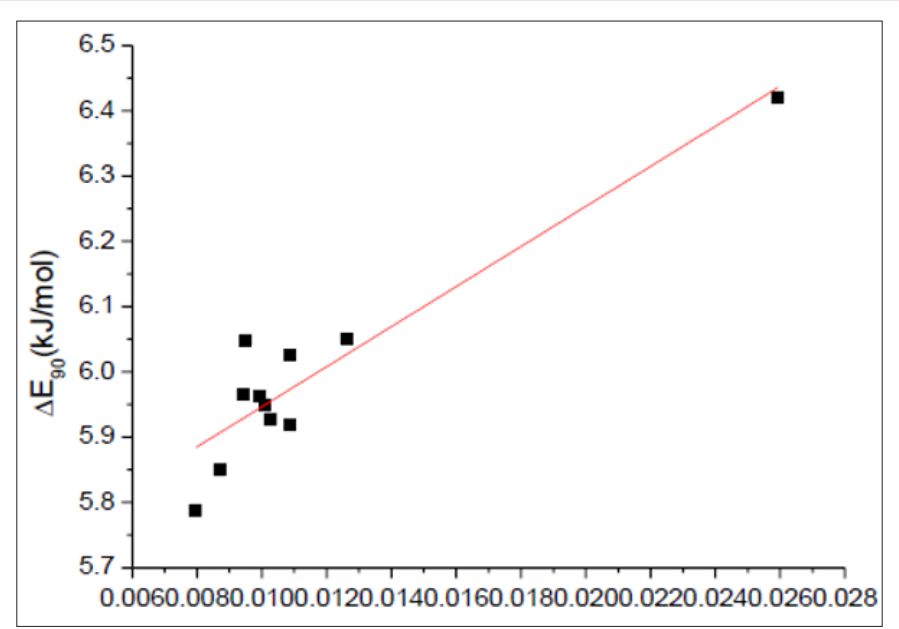

Figure 3: A linear correlation between $\Delta E_{90}$ and $1 / \mathrm{m}^{\prime}$ of biphenyl and compounds $1-10 \Delta E_{90}=(5.63 \pm 0.05)+(31 \pm 4) / \mathrm{m}^{\prime}(\mathrm{kJ} / \mathrm{mol})$ ; $\mathrm{R}=0.92355$; residual sum of squares $=0.03515$.

On the other hand, DE0 of biphenyl was not a simple physical rotation of an object about its center axis. A chemical reaction namely atropisomerization was occurred since the symmetry of the molecule is changed during this rotation as the conversion of R- to S-1,1'-bi-2-naphthyl-2,2'-diol. $\Delta E_{0}$ was fairly correlated with Hammett substituent constant ( $\sigma^{*}$ ) [13] (Figure 4). Therefore, the electronic effect played a role in this mode of rotation as those in six molecules with one ratable dihedral angle: ethane, methylamine, methanol, hydrazine, hydroxylamine, and hydrogen peroxide [14]. Negative $\rho^{*}$ value $(-0.13)$ for this correlation indicated that the transition states $\left(\phi_{=0}\right)$ were more positive charges than ground states $\left(\phi=45^{\circ}\right)$ for these rotations. Electronwithdrawing substituents at the 4 or 4' position of biphenyls would facilitate these rotations. Small absolute value of $\rho^{*}$ implied that the electronic effect occurred far away from the pivot bond of the rotation $\left(\mathrm{C}(1)-\mathrm{C}\left(1^{\prime}\right)\right)$. 


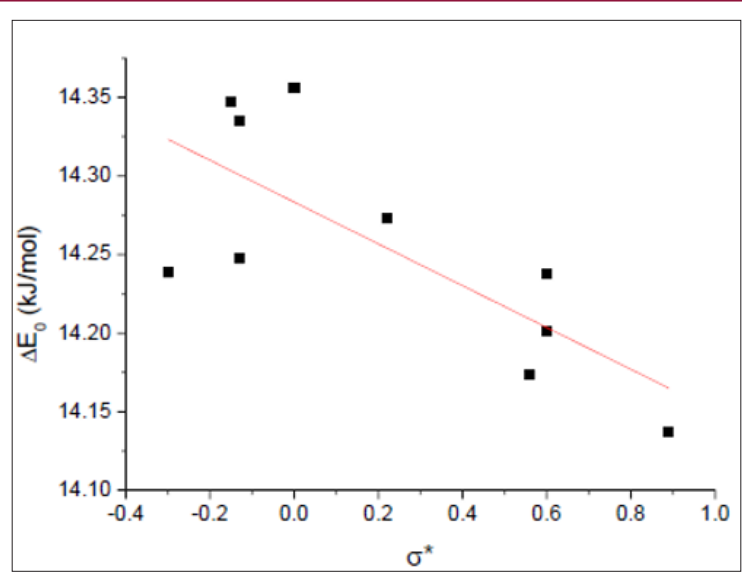

Figure 4: A linear correlation between $\Delta E_{0}$ and $\sigma^{*} \Delta E_{0}=(14.28 \pm 0.02)-(0.13 \pm 0.04) \Delta^{*}(\mathrm{~kJ} / \mathrm{mol})$; $\mathrm{R}=0.70694$; residual sum of squares $=0.0220$.

DFT calculated this activation energy by calculation of the energy difference between ground (dihedral angle, $\phi=45^{\circ}$ ) and transitional (dihedral angle, $\phi=0^{\circ}$ ) states. In other words, this method calculated the reaction as a concerted one-step reaction through a single transition state without a dramatic change in bond length of the $\mathrm{C}(1)-\mathrm{C}\left(1^{\prime}\right)$ pivot bond (Table 2) and (Figure 5). Therefore, $\Delta E_{0}$ was equal to $\Delta \mathrm{E}_{90}$ (rotation energy from physical properties) plus $\Delta$ Evib, where $\Delta$ Evib was the vibrational energy at the mass center near $\phi=0^{0}$.

$$
\Delta E_{0}=\Delta E_{90}+E_{v i b}
$$

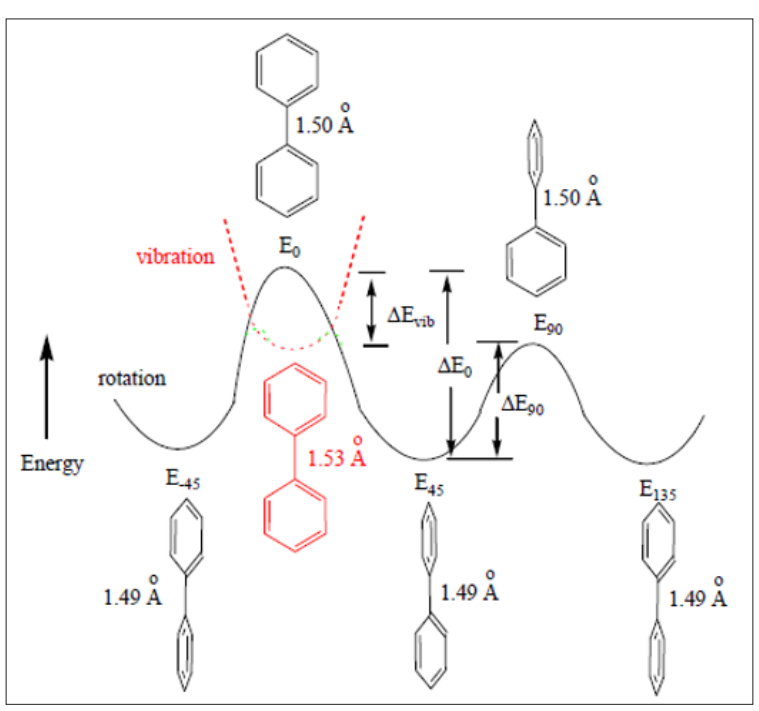

Figure 5: Relative energies and the $\mathrm{C}(1)-\mathrm{C}\left(1^{\prime}\right)$ pivot bond lengths for different conformations of biphenyl.

Table 2: Calculated the $C(1)-C\left(1^{\prime}\right)$ bond lengths of biphenyls for dihedral angles $\phi=00,450$, and 900and the maximum bond length difference $(\Delta x)$ for the $C(1)-C\left(1^{\prime}\right)$ bond stretching at $\phi=00$ (in $\AA$ ).

\begin{tabular}{|c|c|c|c|c|}
\hline \multirow{2}{*}{ Compound } & $C(1)-C\left(1^{\prime}\right)$ & bond & Length & \multirow{2}{*}{$\mathbf{s}$} \\
\hline & $\phi=45^{\circ}$ & $\phi=90^{\circ}$ & $\phi=0^{0}$ & \\
\hline biphenyl & 1.491 & 1.498 & 1.499 & 0.027 \\
\hline 1 & 1.49 & 1.498 & 1.499 & 0.037 \\
\hline 2 & 1.49 & 1.498 & 1.5 & 0.04 \\
\hline 3 & 1.49 & 1.498 & 1.499 & 0.041 \\
\hline 4 & 1.49 & 1.498 & 1.499 & 0.043 \\
\hline 5 & 1.487 & 1.495 & 1.496 & 0.041 \\
\hline
\end{tabular}

Cite this article: Shu-Hsien Lin, Yu-Fang Shen, Chun-Yu Chiou, Gialih Lin, g. Gan-Hong Chen, g. Calculation of Rotational Barriers of 4-Acyloxy- 
However, the transition state of any reaction could not be actually detective by any method because the life time of the transition state was too short. Thus, $\Delta E_{0}$ of biphenyl from experiment was not the activation energy for a single step atropisomerization reaction (Figure 5). Instead, a two-step (two transition states and one intermediate) reaction was proposed for the rotation of biphenyl about its center axis from $\phi=-45^{0}$ to $45^{0}$ through $0^{\circ}$. At dihedral angle near $0 \circ$, the principle of least motion [13] predicted that vibration (or stretching) of the pivot axis, the $\mathrm{C}(1)-\mathrm{C}\left(1^{\prime}\right)$ bond would be more favorable than twisting of the bond. Vibrational energy ( $\left(\mathrm{E}_{\mathrm{vib}}\right)$ could be expressed as Eq. (4), where $\Delta$ and $\mathrm{k}$ were the vibrational quantum number $(\Delta=0,1,2,3, \ldots)$ and force constant, respectively [12].

$$
E_{v i b}=(\Delta+0.5) \hbar\left(k / m^{\prime}\right)^{1 / 2}
$$

Thus, vibrational energy was inversely proportional to the root of reduced mass. A linear correlation between $\Delta E_{0}-\Delta E_{90}$ and $\left(1 / \mathrm{m}^{\prime}\right) 1 / 2$ of biphenyl and compounds $1-10$ was observed (Figure $6)$. Hence, both physical rotation and vibration (or stretching) of the $\mathrm{C}(1)-\mathrm{C}\left(1^{\prime}\right)$ bond played important roles for rotation of biphenyl about the $\mathrm{C}(1)-\mathrm{C}\left(1^{\prime}\right)$ pivot bond from $\phi=-45^{\circ}$ to $45^{\circ}$ near $\phi=0^{0}$. The differences in the $\mathrm{C}(1)-\mathrm{C}\left(1^{\prime}\right)$ bond lengths for the stretching of biphenyl and compounds 1-10 near $\phi=0^{\circ}\left(\mathrm{x}^{\prime} \mathrm{s}\right)$ were calculated to be 0.027-0.046 $\AA$ according to Hooke's law, $\Delta E_{v i b}=(1 / 2) \mathrm{k} \Delta$ $\mathrm{x}^{2}$ (Table 2). Hence, the equilibrium $\mathrm{C}(1)-\mathrm{C}\left(1^{\prime}\right)$ bond length of the intermediate for rotation from $\phi=-45^{0}$ to $45^{0}$ near 0 owas about $1.53 \AA$ (Figure 5). Thus, experimental $\Delta E_{0}$ value of biphenyl (6.0 kJ/ mol) 1 was the about the calculated $\Delta E_{90}$ value $(6.4 \mathrm{~kJ} / \mathrm{mol})$.

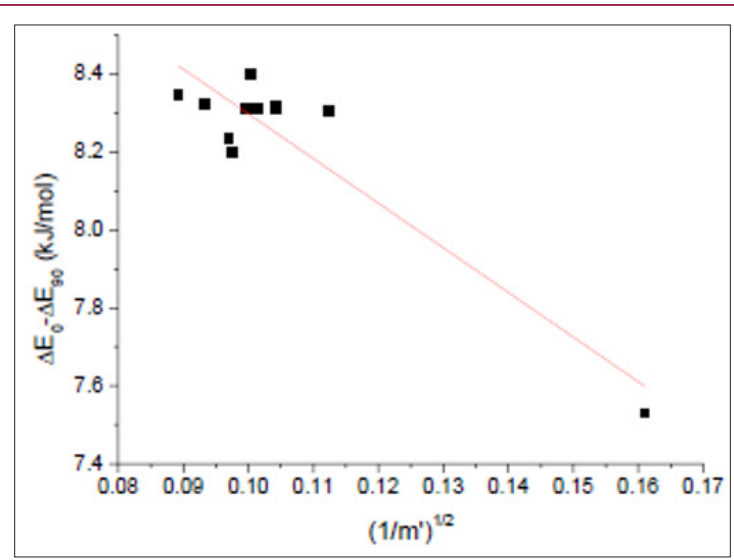

Figure 6: A linear correlation between $\Delta E_{0}-\Delta E_{90}$ and $\left(1 / \mathrm{m}^{\prime}\right)^{1 / 2}$ of biphenyl and compounds 1-10. $\Delta E_{0}-\Delta E_{90}=(9.4 \pm 0.2)-(11.5 \pm 1.5)\left(1 / \mathrm{m}^{\prime}\right)^{1 / 2}(\mathrm{~kJ} / \mathrm{mol}) ; \mathrm{R}=0.9187$; residual sum of squares $=0.08063$.

\section{Acknowledgment}

The authors acknowledge receipt of a grant from the Ministry of Science and Technology (MOST 107-2218-E-468 -005 - and 1072622-E-468 -002 -CC2) of Taiwan. The authors declare that they have no conflicts of interest.s

\section{References}

1. Bastiansen O, Samdal SJ (1985) Structure and barrier to internal rotation of biphenyl derivatives in the gaseous state: Part 2. Structure of 3,3'-dibromo-, 3,5,4' -tribronio- and 3,5,3'5' -tetrabromobiphenyl. Mol Struct 128: 115 .

2. Tsuzuki S, Tanabe KJ (1991) High-level ab initio computations of structures and relative energies of two isomers of the $\mathrm{CO} 2$ trimer. Phys Chem 95: 139.

3. Rubio M, Merchan M, Orti E (1995) A theoretical study of the electronic spectrum of biphenyl. Theor Chim Acta 91: 17.

4. Kapfen A, Choi CH, Kertesz M J (1997) Single-Bond Torsional Potentials in Conjugated Systems: A Comparison of ab Initio and Density Functional Results. Phys Chem A 101: 7426.

5. Tsuzuki S, Uchimaru T, Matsumura K, Mikami M, Tanabe K, et al. (1999) Effects of basis set and electron correlation on the calculated interaction energies of hydrogen bonding complexes: MP2/cc-pV5Z calculations of $\mathrm{H}_{2} \mathrm{O}-\mathrm{MeOH}, \mathrm{H}_{2} \mathrm{OO}-\mathrm{Me}_{2} \mathrm{O}, \mathrm{H}_{2} \mathrm{O}-\mathrm{H}_{2} \mathrm{CO}, \mathrm{MeOH}-\mathrm{MeOH}$, and $\mathrm{HCOOH}-\mathrm{HCOOH}$ complexes J Chem Phys 110: 2858.
6. Johansson MP, Olsen JJ (2008) Torsional Barriers and Equilibrium Angle of Biphenyl: Reconciling Theory with Experiment. Chem Theory Comput 4: $1460-1471$.

7. Lin G, Chen GH, Yeh SC, Lu CP (2005) Probing the peripheral anionic site of acetylcholinesterase with quantitative structure activity relationships for inhibition by biphenyl-4-acyoxylate-4'-N-Butylcarbamates. J Biochem Mol Toxicol 19: 234-243.

8. Lin G, Chen GH, Lu CP, Yeh SC (2005) Quantitative structure-activity relationships for the pre-steady state of Pseudomonas species lipase inhibitions by p-nirophenyl-N-substituted carbamates. QSAR Comb Sci 24: 943 .

9. Lin G, Chen GH, Lin YF, Su LS, Liao PS, et al. (2005) Long-Term Risk of Coronary Events after AKI. Eur J Lipid Sci Technol 107: 65.

10. Frisch MJ, Trucks GW, Schlerel HB, Scuseria GE (2003) Influence of Mg2+, Fe2+ and Zn2+ Cations on 13C-180 Bonds in Precipitated Aragonite, Calcite and Dolomite: An ab Initio Study GAUSSIAN 03 (Revision B.01) Gaussian, Inc Pittsburgh PA.

11. Leo A, Hansch C, Elkins D (1971) Partition coefficients and their uses. Chem Rev 71: 525-616.

12. Beiser A (2003) Concepts of Modern Physics ( $6^{\text {th }}$ edn.) McGraw-Hill New York, USA.

13. Isaacs N (1995) Physical Organic Chemistry (2 ${ }^{\text {nd }}$ edn.) Longman Essex.

14. Liu SJ (2013) An introduction to sensitivity analysis for unobserved confounding in nonexperimental prevention research. Phys Chem A 14(6): 170-180. 


\section{ISSN: 2574-1241}

DOI: 10.26717/BJSTR.2019.13.002332

Gan-Hong Chen. Biomed J Sci \& Tech Res

(c) (P) This work is licensed under Creative

Submission Link: https://biomedres.us/submit-manuscript.php

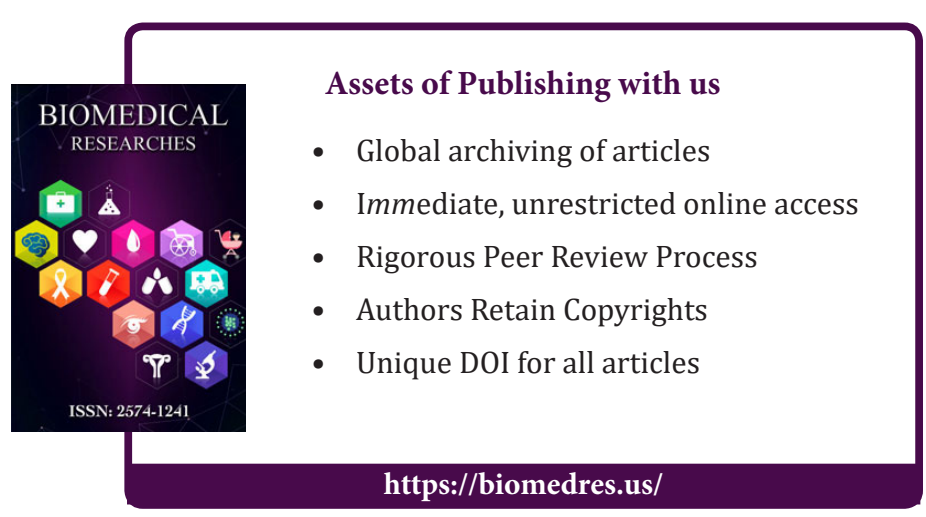

